\title{
Role of cellulose nanocrystals in epoxy-based nanocomposites: mechanical properties, morphology and thermal behavior
}

\author{
Nayra Reis do Nascimento ${ }^{1}$ (D), Ivanei Ferreira Pinheiro ${ }^{1}$ (D), Guilherme Fioravanti Alves ${ }^{1}$ (D), \\ Lucia Helena Innocentini Mei ${ }^{1}$ (D), José Costa de Macedo Neto ${ }^{2 *}$ (D) and Ana Rita Morales ${ }^{1 *}$ (D) \\ 'Laboratório de Blendas e Compósitos Poliméricos, Departamento de Engenharia de Materiais e \\ Bioprocessos, Universidade Estadual de Campinas - UNICAMP, 13083-852, Campinas, SP, Brasil \\ ${ }^{2}$ Laboratório de Materiais e Processamento, Departamento de Engenharia de Materiais, \\ Universidade do Estado do Amazonas - UEA, 69050-020 Manaus, AM, Brasil \\ *morales@unicamp.br; jmacedo@uea.edu.br
}

\begin{abstract}
This study evaluated the influence of cellulose nanocrystals (CNC) content on the properties of epoxy nanocomposites. The CNC were obtained from microcrystalline cellulose by acid hydrolysis. 4.0, 5.5 and $7.0 \%$ of untreated CNC were incorporated into epoxy resin. Sonication was used to disperse the CNC in the resin. The thermal stability, the glass transition temperature and the degree of conversion were reduced as observed by Thermogravimetry and Differential Scanning Calorimetry, respectively. The tensile and bending modulus showed no significant improvement and the impact resistance showed a slight reduction due to the non-uniform dispersion of the CNCs, as observed by Transmission Electron Microscopy. Analysis of Scanning Electron Microscopy showed a change of the fracture mechanism of the epoxy resin: the CNCs increased the elastic modulus by reinforcement, but accelerated the fracture by acting as defects. The Halpin-Tsai model was applied to predict the elastic modulus of the epoxy/CNC system.
\end{abstract}

Keywords: cellulose nanocrystals, nanocomposites, epoxy resin.

How to cite: Nascimento, N. R., Pinheiro, I. F., Alves, G. F., Mei, L. H. I., Macedo Neto, J. C., \& Morales, A. R. (2021). Role of cellulose nanocrystals in epoxy-based nanocomposites: mechanical properties, morphology and thermal behavior. Polímeros: Ciência e Tecnologia, 31(3), e2021034. https://doi.org/10.1590/0104-1428.20210057

\section{Introduction}

The development of high-performance polymers has focused on materials that are reinforced with nanoparticles that can improve the properties in relation to those made with pure materials. Polymeric nanocomposites are materials that contain fillers, in which at least one of their dimensions has measurements that is less than $100 \mathrm{~nm}$, dispersed in a polymer matrix ${ }^{[1]}$. They are part of a class of engineering materials that are very attractive because they provide better mechanical and thermal properties than conventional composites. In addition, only small amounts of reinforcement are required ${ }^{[2,3]}$. Cellulose nanocrystals $(\mathrm{CNCs})$ are one of these particles that are used because they have a set of peculiar characteristics that characterize them as a good polymer matrix-reinforcing agent. These characteristics are the following: a high amount of hydroxyl groups that can provide the possibility of very good interaction in the polymer/filler interface; a high specific surface area and high aspect ratio that is important to stress transfer; high crystallinity and elastic modulus, which are responsible for the increase in stiffness; as well as high thermal stability, low cost, low density and a peculiarly interesting morphology ${ }^{[4]}$.
Due to the excellent properties of CNCs, many studies have been developed that show their use as nanofillers in polymers. The high polarity and high hydrophilicity nature of CNCs causes the interaction and dispersion in some types of polymeric matrices to be compromised ${ }^{[4]}$. Polar matrices can present better dispersion of the CNCs due to the high interaction of hydrogen bonds, thus obtaining better mechanical properties ${ }^{[5]}$, while nonpolar matrices can present worse dispersion and reduced mechanical properties.

Many studies have shown that CNC surfaces treated with organic compounds have a better interaction with non-polar polymers ${ }^{[6]}$. However, in order to promote better interaction with the polymeric matrix, treated CNCs are used in liquid suspension ${ }^{[7]}$. Another factor that influences the dispersion of $\mathrm{CNCs}$ in the polymer matrix is the method used for obtaining it. Some methods of obtaining nanocomposites use complex equipment such as extrusion and hot pressing ${ }^{[7]}$. In this study, the CNCs were inserted in the polymeric matrix in the form of a dry powder and the nanocomposites were obtained by a simple method of manual mixing at room temperature.

CNCs are extracted from cellulose, which is the most abundant natural polymer in nature. Among other sources, 
they can be extracted from microcrystalline cellulose (MCC), which is a substance obtained from partially depolymerized cellulose. It can be dried to a fine, powdery particle form or co-processed with a water-soluble polymer to form a colloid. MCC is widely used because it is chemically stable and physiologically inert ${ }^{[8]}$. As such, there has been increased interest in its use in the pharmaceutical ${ }^{[9]}$, food industries and the energy sector ${ }^{[10]}$.

Epoxy resin was chosen as the nanocomposite matrix for this study. Epoxy resin is part of an important class of highperformance thermosetting polymers that are widely used in automotive, construction and aerospace applications ${ }^{[11]}$. It is considered one of the best matrices since it has excellent properties such as good adhesion ${ }^{[12]}$, good mechanical properties such as high elastic modulus, shear strength, corrosion resistance, thermal stability, low shrinkage after the curing process, favorable viscosity properties, light weight, low cost, resistance to environmental degradation, as well as good friction and wear resistance ${ }^{[13]}$.

The incorporation of CNCs in the epoxy resin can result in a high stiffness and good fatigue strength, which, for example, is very desirable in aerospace applications. Studies in which CNCs from tunicates and cotton were incorporated into the epoxy matrix showed good dispersion and consequent improvement in mechanical properties due to the increased in interfacial adhesion between the $\mathrm{CNCs}$ and the epoxy matrix ${ }^{[14]}$.

Roszowska-Jarosz et al. ${ }^{[15]}$ describe the production of epoxy/ $\mathrm{CNC}$ nanocomposites by adding a suspension of $\mathrm{CNCs}$ and acetone in the quantities of $0.5 \%, 1 \%$ and $1.5 \%$ wt in epoxy resin, for which they obtained superior values for impact resistance and flexural strength. Nissilä et al. ${ }^{[16]}$ produced nanocomposites by impregnating cellulose nanofibers (CNF) in bio-epoxy resin. For this, they produced suspensions in water in the quantities of 1.0 and $1.5 \%$ wt of CNF and then they prepared aerogels by freezing the suspensions in molds. The frozen suspensions were impregnated with the bio-epoxy resin using a vacuum and its curing was carried out at $80{ }^{\circ} \mathrm{C}$. Data on the mechanical properties were obtained by tensile and flexion tests in which the nanocomposites showed an increase in the flexural modulus of approximately $50 \%$, and of $20 \%$ in the tensile strength in relation to the polymer without CFN. Qi et al. ${ }^{[17]}$ produced $\mathrm{CNC} /$ epoxy nanocomposites using superficially modified $\mathrm{CNCs}$ by grafting with poly (n-vinylpyrrolidone), which significantly increased the toughness of epoxy resin and is explained by the excellent dispersion of the CNCs and its effect in promoting plastic deformation in the system. Some other works mention the modification of epoxy resin with CNCs identifying, in addition to changes in mechanical properties, changes in thermal characteristics ${ }^{[18]}$.

The objective of this study was to characterize the CNCs obtained from MCC and evaluate the mechanical properties of epoxy/CNC nanocomposites considering the influence of the $\mathrm{CNC}$ volumetric fraction, taking into account fractions in above, and below the percolation threshold. The HalpinTsai modulus of elasticity prediction model was applied as a tool to understand the interactions of the components and the mechanical behavior of the system under study.

\section{Material and Methods}

\subsection{CNC production}

Commercial microcrystalline cellulose (MC 500, Blanver, Brazil) was used as a source of cellulose for CNC extraction. Sulfuric acid (Synth) was used in the acid hydrolysis process. The nanocomposites were produced using DER 331 bisphenol A diglycidyl ether-based (DGEBA) epoxy resin and the hardener DEH 24, a triethylenediamine (Dow Chemical Company), which were mixed in the ratio of 100:13, as indicated by the supplier.

Acid hydrolysis consists of a process that removes the amorphous phase of cellulose so that the nanocrystals are isolated. Microcrystalline cellulose was hydrolyzed with sulfuric acid solution $(55 \% \mathrm{v} / \mathrm{v})$ at $45{ }^{\circ} \mathrm{C}$ for $30 \mathrm{~min}$ under constant stirring, then, $300 \mathrm{~mL}$ of distilled water was added to stop the reaction, following the Hassan method ${ }^{[19]}$. The ratio was $10 \mathrm{~mL}$ of sulfuric acid solution to $1 \mathrm{~g}$ of microcrystalline cellulose.

Centrifugation was applied to partially remove sulfuric acid and separate the nanocrystals from the solution. The supernatant that appeared after 10 minutes of each centrifugation cycle at $6000 \mathrm{rpm}$ was removed and replaced with distilled water. This exchange procedure was performed repeatedly until the solution reached a $\mathrm{pH}$ close to 7 . The resulting suspension was submitted to dialysis. The material was placed on the dialysis membrane so that the exchange with the aqueous medium occurred. The water, where the membranes were immersed, was replaced once after $24 \mathrm{~h}$ and dialysis continued for a further $24 \mathrm{~h}$. As the last step, lyophilization consisted of the total removal of water using a freeze dryer, which left only the powdered nanocrystals. From this step, the CNCs were ready to be incorporated into the epoxy matrix. During this stage, CNCs tend to cluster together in structures that are stabilized by hydrogen interactions. Freeze-drying was the method of drying used, and this allows the dispersed $\mathrm{CNC}$ material structure to be maintained.

\subsection{Nanocomposites production}

Nanocomposites with a CNC volumetric concentration of $4.0,5.5$ and $7.0 \%$ were prepared. These concentrations were determined from the theoretical calculation of the percolation threshold ${ }^{[20]}$. The CNCs were weighed and carefully added to the epoxy resin, then manually mixed at room temperature, according to the work of Omrani et al. ${ }^{[21]}$. An ultrasonic probe (QSONICA, Q700, USA) was used with a maximum power of $700 \mathrm{~W}$ and a $6.4 \mathrm{~mm}$ diameter sonotrode for $10 \mathrm{~min}$. to fully disperse the $\mathrm{CNCs}$ in the polymer matrix under $30 \mathrm{~W}$ power conditions. Then, the hardener was added and mixed evenly with the resin. Figure 1 shows a schematic of the steps in the production of nanocomposites. The mold used was produced in aluminum alloy with dimensions of $30 \times 30 \times 1.5 \mathrm{~cm}$ and its cavities in the shapes and dimensions of specimens for mechanical tests were produced by machining (Figure 2). As a release agent, PVC film was used inside the mold. The mixture was poured into the mold and kept at room temperature at atmospheric pressure for curing. 


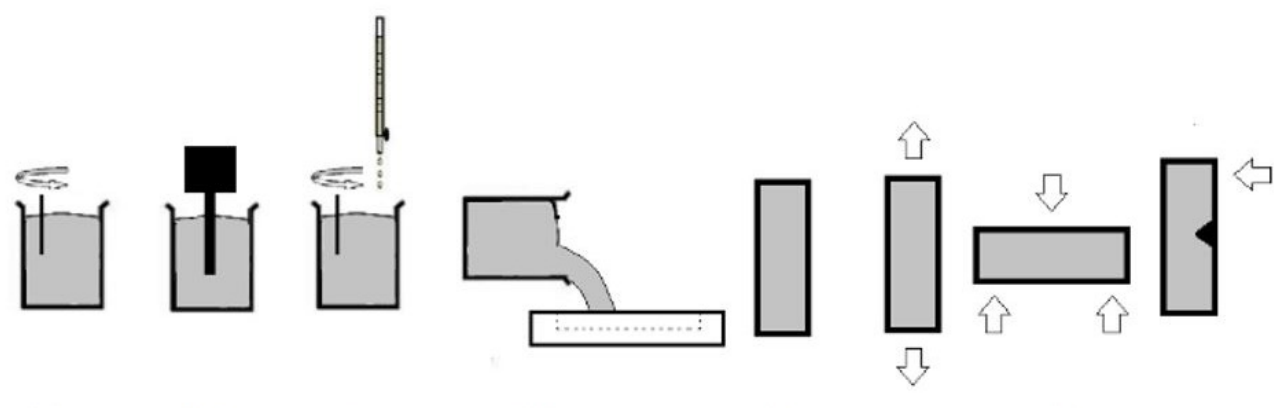
(a)
(b)
(c)
(d)
(e)
(f)

Figure 1. (a) Manual mixing of CNCs and epoxy resin; (b) ultrasonic CNC dispersion; (c) manual addition and mixing of hardener; (d) the mixture poured into the mold; (e) specimen after curing and (f) mechanical testing.
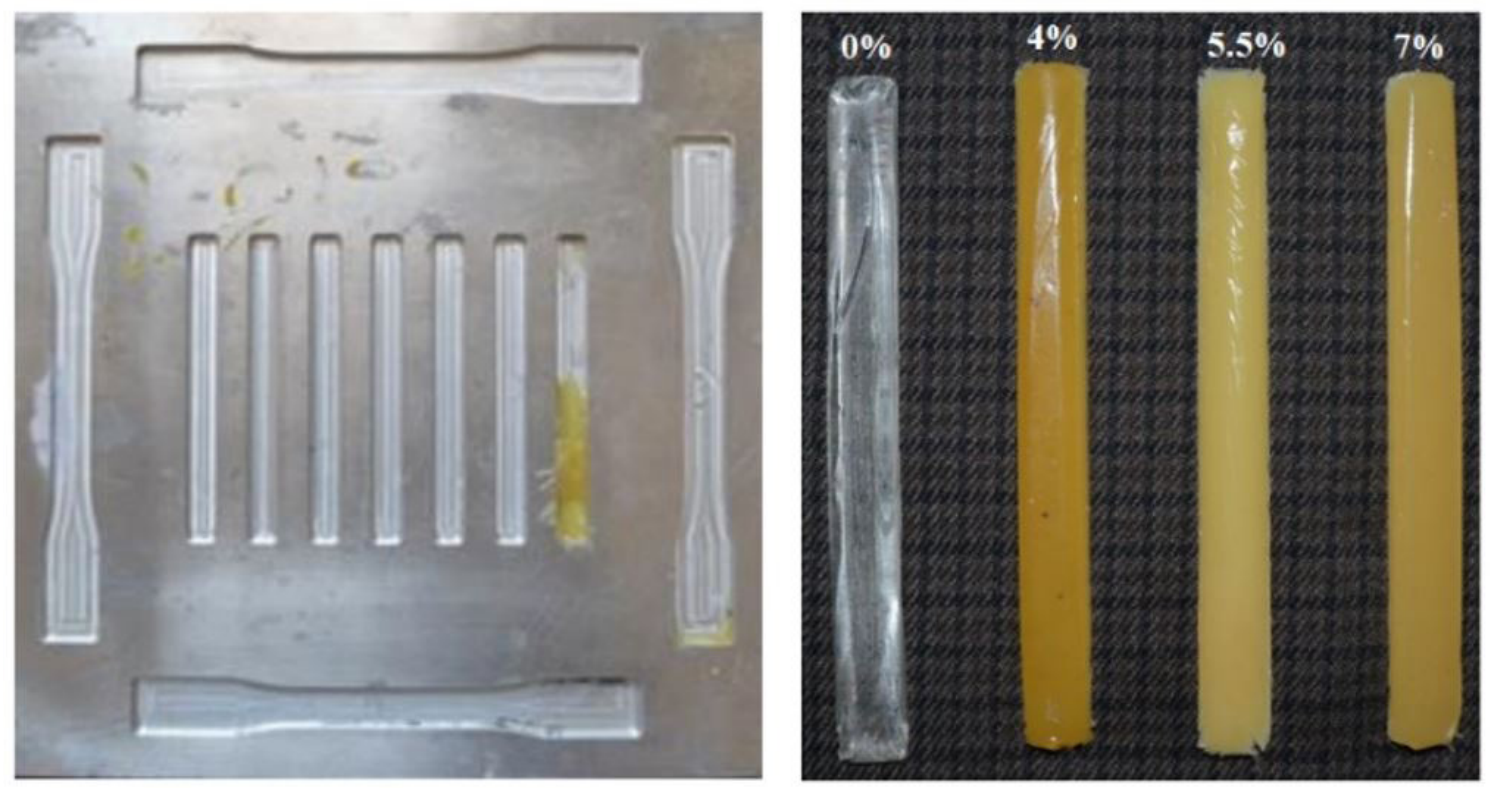

Figure 2. Metal mold and specimens produced.

\subsection{CNCs and nanocomposite characterization}

The samples of CNCs obtained were analyzed by using Fourier transform infrared spectroscopy (FTIR) (Nicolet 6700, Thermo Scientific, USA). The spectra were obtained in the ATR mode, with the SMART OMNI-SAMPLER accessory operating in the $4000-675 \mathrm{~cm}^{-1}$ range, with $4 \mathrm{~cm}^{-1}$ resolution and 128 scans.

Transmission electron microscopy (TEM) (JEM 2100, JEOL, Japan) was used to evaluate the morphology of the CNCs. To obtain the TEM image, a drop of the diluted CNC suspension was allowed to dry on a carbon-coated copper grid (400 mesh). To improve contrast, a $2 \%$ by weight solution of uranyl acetate was placed on the grid for 30 seconds.

For determination of the aspect ratio (L/D), dimensions of the CNCs were obtained from TEM images with the aid of Image J software. For this calculation, about 60 units of CNCs were used.
The crystal structure of the CNCs was evaluated using X-ray diffraction analysis (XRD), (X'Pert-MPD, Philips, USA), operating with $\mathrm{CuK} \alpha(\lambda=1.54060 \AA), 40 \mathrm{kV}$ voltage and $40 \mathrm{pA}$ current, $2 \theta$ between 5 and $50^{\circ}$. The samples were placed in the XDR equipment in dry powder form. The degree of crystallinity was estimated following the method cited by Martin et al. ${ }^{[22]}$ as it is widely used for natural fibers. The index $\left(\mathrm{I}_{\mathrm{c}}\right)$ was estimated by means of Equation 1.

$$
I_{\mathrm{c}}=1-\left(\frac{\mathrm{I}_{\mathrm{am}}}{\mathrm{I}_{002}}\right) \times 100
$$

Using the peaks $\left(\mathrm{I}_{002}, 2 \theta=22.4^{\circ}\right)$ and $\left(\mathrm{I}_{\mathrm{am}}, 2 \theta=18.8^{\circ}\right) . \mathrm{I}_{002}$ represents both the crystalline and the amorphous material, while $\mathrm{I}_{\mathrm{am}}$ represents amorphous material.

The nanocomposites obtained were analyzed using FTIR (Nicolet 6700, Thermo Scientific, USA). Infrared spectra were obtained in ATR mode, with the SMART OMNI- 
SAMPLER accessory operating in the $4000-675 \mathrm{~cm}^{-1}$ range, with $4 \mathrm{~cm}^{-1}$ resolution and with 128 scans.

To evaluate the thermal behavior, DSC equipment (DCS1, Mettler Toledo, Switzerland) was used with a heating rate from $10{ }^{\circ} \mathrm{C} / \mathrm{min}$ from -30 to $300{ }^{\circ} \mathrm{C}$ and an inert atmosphere $\left(\mathrm{N}_{2}\right)$ with a flow of $50 \mathrm{ml} / \mathrm{min}$. Firstly, the total cure enthalpy of the base system was obtained from the DSC analysis of the resin + hardener in the range of -30 to $300{ }^{\circ} \mathrm{C}$ in the proportions indicated by the manufacturer, which was found to be $4592 \mathrm{~mJ}$.

The nanocomposites were also evaluated using a thermogravimetric analyzer (TG) (TGA-50M, Shimadzu, Japan) and a microanalytical scale (MX5, Mettler Toledo, Switzerland). Analyses were performed in an inert atmosphere $\left(\mathrm{N}_{2}\right)$, in a temperature range of 25 to $600{ }^{\circ} \mathrm{C}$, and a heating rate of $10^{\circ} \mathrm{C} / \mathrm{min}$.

The morphology and size distribution of the particles in the CNC filled epoxy nanocomposites were studied by using TEM (TECNAI T20, FEI, USA) with $200 \mathrm{kV}$. In this analysis, the samples with $4.0,5.5$ and $7.0 \%$ of CNCs was cut in thin sections (around $120 \mathrm{~nm}$ in thickness) using an ultramicrotome (UltraCut, Leica, Austria) and placed on a copper grid of $3 \mathrm{~mm}$ in diameter.

A universal testing machine was used to obtain the tensile mechanical properties of modulus of elasticity $\left(\mathrm{E}_{\mathrm{T}}\right)$, tensile strength $\left(\sigma_{\mathrm{T}}\right)$ and strain at break $\left(\varepsilon_{\mathrm{T}}\right)$. Samples were prepared according to ASTM D638-10, Type I, and an extensometer (High Elongation extensometer AHX850, MTS, USA) was used. For each formulation, five specimens were tested and the average value was calculated. The universal test machine (Alliance RT/5, MTS, USA) operated at a crosshead speed of $1 \mathrm{~mm} / \mathrm{min}$ and a $5 \mathrm{kN}$ load cell was used.

Flexural tests of the samples were performed and flexural modulus $(E F)$ and flexural strength $(\sigma F)$ were evaluated. For each formulation, five specimens were tested and the average value was calculated. The 3-point bending tests were performed at room temperature according to ASTM D790-03. A universal testing machine (5984, Instron, USA) was used with a $150 \mathrm{kN}$ load cell and at speed of $2 \mathrm{~mm} / \mathrm{min}$.

For determination of the impact strength (IS) the samples were prepared according to ASTM D4812-19 and the notched Izod test was performed using an impact tester (Impact 104, Tinius Olsen, USA) with capacity of $25 \mathrm{~J}$ and a $10^{\circ}$ impact hammer.

The nanocomposite fractured surface morphology was studied using scanning electron microscopy (SEM) (LEO 440i, Leica, England) at $10 \mathrm{~mA}$ operating current.

The samples from the tensile test were cut at $5.0 \mathrm{~mm}$ (manual cutter) below and parallel to the fracture. The cut piece was fixed with carbon adhesive on the SEM sample holder and was gold sputter coated with a sputter coater (SC7620, Polaron VG Microtech, UK) with a film of approximately $20-50 \mathrm{~nm}$.

\section{Results and Discussion}

\subsection{CNC characterization}

Figure 3 shows the comparative FTIR spectra of the MCC and the CNCs. In the MCC spectrum, the band around $3400 \mathrm{~cm}^{-1}$, which is due to the $\mathrm{OH}$-stretching vibration, is typical for adsorbed water and gives considerable information concerning the hydrogen bonds. The band at $2900 \mathrm{~cm}^{-1}$ corresponds to the stretching of the $\mathrm{C}-\mathrm{H}$ bonds. The bands at 1430,1059 and $897 \mathrm{~cm}^{-1}$ are typical of pure cellulose and can be seen in both the MCC and CNC spectrum. In general, the $897 \mathrm{~cm}^{-1}$ band is assigned to vibrations of the C-O-C elongations of the characteristic $\beta(1 \rightarrow 4)$ glycosidic bond ${ }^{[23]}$. Therefore, typical cellulose bands can be seen in both the MCC and $\mathrm{CNCs}^{[24]}$.

Figure 4 shows the results of X-ray diffraction of the $\mathrm{CNCs}$ and the MCC. A peak at $22.42^{\circ}$ can be observed and indicates the presence of crystallinity that is characteristic of this nanoparticle. This peak refers to cellulose type I and approaches the value of $22.7^{\circ}$ found in the literature ${ }^{[25]}$. This means that the CNCs were isolated from other parts of the cellulose and that the acid hydrolysis process did not change their structure during treatment. The degree of crystallinity obtained was $82.7 \%$. The degree of crystallinity was calculated following the method cited by Martin et al. ${ }^{[22]}$ and is widely used for natural fibers. One shoulder can also be observed on the diffractogram around $20^{\circ}$, which refers

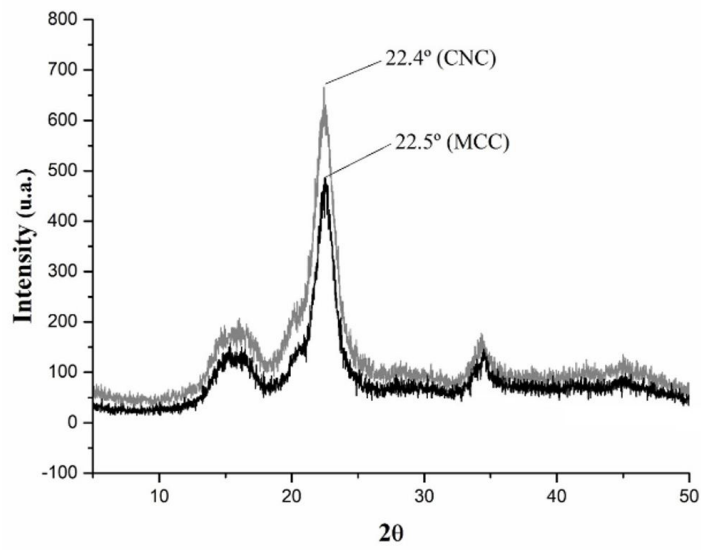

Figure 4. Diffractogram of the CNCs and the MCC.
Figure 3. CNC and MCC FTIR spectra.

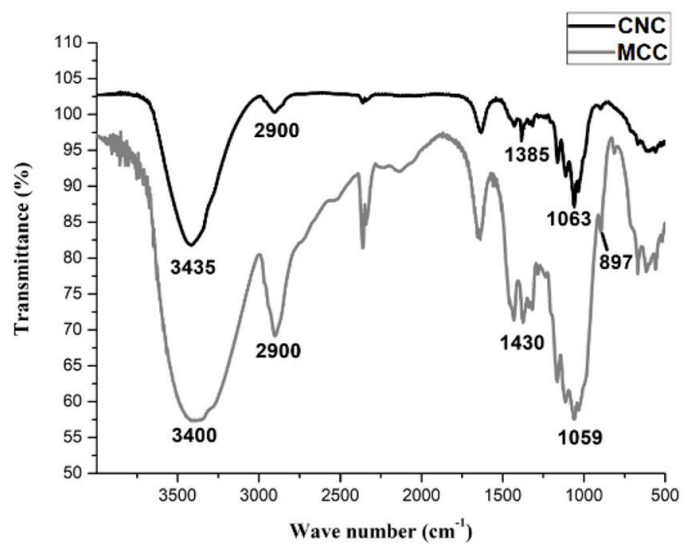


to cellulose type II that could be present in low amounts. At peak $22.5^{\circ}$ of the MCC, a lower intensity is observed and this may indicate the presence of amorphous regions ${ }^{[26]}$.

Figures 5a-c show the image from the TEM that was performed after the CNCs were lyophilized. It can be observed that the nanocrystals were obtained successfully. The image shows the needle-like nanoparticles that correspond to the characteristic and expected morphology of the CNCs. It can also be noted that there was some level of agglomeration of particles and consequent stacking on each other. The CNC agglomeration phenomenon is mainly due to their very small size and their very high surface energy. In addition, the hydroxyl group on the surface of the CNCs facilitates the formation of hydrogen bonds, which facilitates their approximation.

The morphology of the CNCs is shown in Figure 5. The length (L) and diameter (D) of the CNCs were (142 \pm 36$)$ $\mathrm{nm}$ and $(11 \pm 2.5) \mathrm{nm}$, respectively. A total of 60 length and diameter measurements were taken and then the aspect ratio (L/D) was calculated from each measurement. Thus, the aspect ratio obtained was 12.5. A high aspect ratio results in high rigidity of the percolated nanoparticle network and this favors the reinforcing effect on a nanocomposite since a good dispersion is obtained in polymer matrices. In order to have a good transfer of tensions between the matrix and the reinforcement, the minimum value of the aspect ratio must be $10^{[27]}$, which was obtained in this work however, other aspects, such as the compatibility between the matrix and the dispersed phase, the percolation limit and the dispersion, must be considered ${ }^{[20]}$. CNCs have a tendency to aggregate, as seen in Figure 5.

\subsection{Nanocomposite characterization}

In order to understand the relationship between processing, morphology, properties and durability of a thermoset material and, consequently, of the composite, it is necessary to understand the cure mechanism of the system. Table 1 summarizes the DSC data. Tg values of the nanocomposites were reduced by $5{ }^{\circ} \mathrm{C}$ for the samples with 5.5 and $7.0 \%$ of CNCs in relation to pure epoxy. Residues of water molecules on the surfaces of CNC aggregations may have affected the crosslinking of the epoxy matrix ${ }^{[28]}$.
As Tg was influenced by the presence of the CNCs, it can be assumed that the nanocomposite can be processed under the same conditions as the neat system and that the thermal behavior under the application conditions would be close.

The samples were cured at room temperature. An important point is that, for all samples, the relaxation enthalpy was observed and the cure was not complete. The conversion for each sample was determined following the method of Hardis et al. ${ }^{[29]}$. The values are shown in Table 1, in which it is observed that the conversion is very similar for all samples, although the presence of $(-\mathrm{OH})$ groups of cellulose may participate in the curing reaction of the epoxy resin and result in increased conversion ${ }^{[29}$. It is possible that this effect was diminished by the spatial restriction caused by the CNCs.

In order to understand the chemical structure of epoxy resin and especially nanocomposites in more detail, the FTIR spectra were evaluated. Figure 6 shows the spectra of epoxy and nanocomposites with different $\mathrm{CNC}$ contents. The epoxy group has three characteristic absorption bands in the infrared spectrum. One is the band appearing in the $1250 \mathrm{~cm}^{-1}$ range, which corresponds to the symmetrical axial deformation of the epoxy ring and the aromatic ether group $\mathrm{C}-\mathrm{O}-\mathrm{C}$, in which all its bonds expand and contract in phase $\mathrm{e}^{[30]}$. Another is the $916 \mathrm{~cm}^{-1}$ band, which is related to the asymmetric axial deformation of the ring, in which the $\mathrm{C}-\mathrm{C}$ bond increases and the $\mathrm{C}-\mathrm{O}$ bond contracts. The third band appears in the $840-750 \mathrm{~cm}^{-1}$ range and corresponds to the C-O-C bond ${ }^{[31]}$. The absorption present in the 3000$3500 \mathrm{~cm}^{-1}$ range refers to the hydroxyl groups of adsorbed water that were identified in all the nanocomposites. The absorption around $2925 \mathrm{~cm}^{-1}$ is due to the stretching of C-H

Table 1. Results of thermal analysis: glass transition temperature $(\mathrm{Tg})$, residual enthalpy $\left(\Delta H_{R}\right)$ and conversion degree $(\mathrm{X})$.

\begin{tabular}{cccc}
\hline *V CNC (\%) & Tg $\left({ }^{\circ} \mathbf{C}\right)$ & $\begin{array}{c}\Delta \boldsymbol{H}_{\boldsymbol{R}} \\
(\mathbf{m J} / \mathbf{m g})\end{array}$ & $\mathbf{X}(\%)$ \\
\hline 0 & 67 & 123 & 97 \\
4 & 67 & 182 & 96 \\
5.5 & 63 & 249 & 95 \\
7 & 63 & 243 & 95 \\
\hline
\end{tabular}

*CNC volumetric concentration (\%).

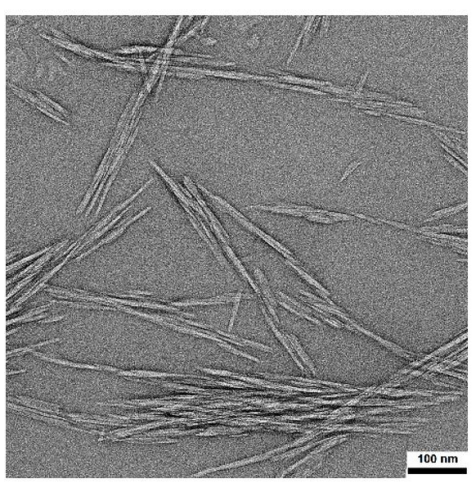

(a)

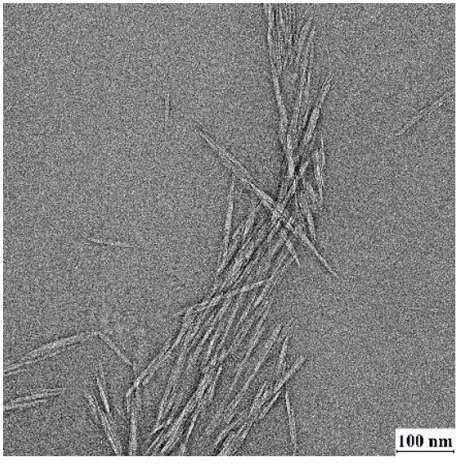

(b)

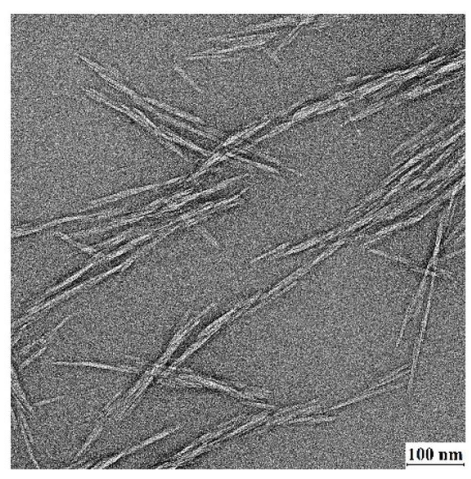

(c)

Figure 5. (a), (b), (c) Transmission electron micrographs of the obtained CNCs. 
bonds. Strong absorptions between 1000 and $1250 \mathrm{~cm}^{-1}$ indicate the C-O-C (ether) or C-O-H groups. The bands in the $2900-2930 \mathrm{~cm}^{-1}$ range indicate stretching of C-H bonds. Monitoring the band at $916 \mathrm{~cm}^{-1}$ allowed us to evaluate the existence of residual epoxy groups, which indicate if the cure was complete with the consumption of most groups. As can be seen in Figure 6, this band almost disappeared in the nanocomposite spectra. This means that there was a small cure residual, as observed in the DSC analysis. All the $\mathrm{CNCs}$ /epoxy nanocomposites at different filler loadings displayed similar FTIR spectra.

The interfacial interaction of the CNCs and epoxy resin can be evaluated using FTIR. A reduction in bands between 3000-3500 $\mathrm{cm}^{-1}$ was observed for nanocomposites. These bands refer to the hydroxyl groups adsorbed on the surface of the CNCs. This behavior indicates that there may have been a low interfacial interaction between the CNCs and the epoxy in the production of the nanocomposites ${ }^{[1]}$, although the CNCs were expected to be trapped in the cross-linked epoxy resin and completely covered by the polymer chains via hydrogen bonds ${ }^{[18]}$. The TEM images confirm the low interaction and, as a consequence, the formation of clusters. This low interaction may have affected the mechanical and

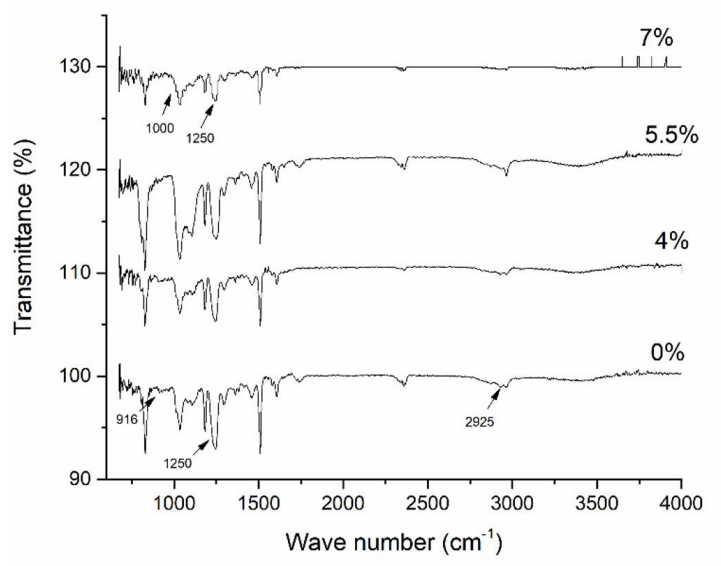

Figure 6. FTIR spectra of pure epoxy resin and nanocomposites. thermal properties of the nanocomposites, making them inferior to CNC-free epoxy and this will be discussed later.

The thermal stability of the pure epoxy resin and the nanocomposites was evaluated using TG analysis. Figure 7 shows the degradation temperature curves, and the results are presented in Table 2. It is observed that there was a initial mass reduction for temperatures between $50-200^{\circ} \mathrm{C}$, which was due to moisture loss from the dehydration of secondary alcoholic groups and the evaporation of physically weak and loosely bound moisture on the surfaces of the composites ${ }^{[32]}$.

Table 2 shows that the moisture loss was greater for the nanocomposites than for the pure epoxy. This behavior suggests that the $\mathrm{CNCs}$ adsorbed water on their surface. It was also observed that the moisture loss values are close to those of the nanocomposites, which suggests that the amount of water did not increase when the CNC fractions increased. The interaction of the epoxy resin matrix acted as a water barrier that prevented the attraction with the hydrophilic hydroxyls on the surface of the CNCs. CNC aggregations in the epoxy matrix may also have prevented access to water on the surface of the $\mathrm{CNCs}^{[33]}$.

Thermal decomposition of pure epoxy resin occurs in two stages ${ }^{[34]}$. The main mass loss occurs in the range of 300 to $500{ }^{\circ} \mathrm{C}$, which involves two stages of degradation. The initial loss peak around $350{ }^{\circ} \mathrm{C}$ corresponds to the degradation of the aliphatic amine curing agent due to its low $\mathrm{C}-\mathrm{N}$ bond breakage energy. The second peak occurs in the temperature range of $405^{\circ} \mathrm{C}$ and is attributed to resin decomposition ${ }^{[18]}$.

Table 2. Results of the TG analysis.

\begin{tabular}{cccccc}
\hline $\begin{array}{c}\text { VCNC } \\
(\%) * * * *\end{array}$ & $\begin{array}{c}\mathbf{T}_{\text {moisture loss }} \\
\left({ }^{(} \mathbf{C}\right)\end{array}$ & $\begin{array}{c}\text { Moisture } \\
\text { loss (\%) }\end{array}$ & $\begin{array}{c}\mathbf{T}_{\text {onset }}{ }^{*} \\
(\%)\end{array}$ & $\begin{array}{c}\mathbf{T}_{5 \%}{ }^{* * *} \\
\left({ }^{\circ} \mathbf{C}\right)\end{array}$ & $\begin{array}{c}\mathbf{T}_{\max }{ }^{* * *} \\
\left({ }^{\circ} \mathbf{C}\right)\end{array}$ \\
\hline 0 & $58-150$ & 1.9 & 356 & 338 & 390 \\
4 & $62-205$ & 2.2 & 354 & 336 & 397 \\
5.5 & $44-126$ & 2.1 & 344 & 312 & 382 \\
7 & $65-200$ & 2.0 & 353 & 319 & 387 \\
\hline $\mathrm{T}_{\text {onset }} *$ : the onset temperature of weight loss; $\mathrm{T}_{5 \%} * *$ : the temperature \\
corresponding to 5\% of weight loss; $\mathrm{T}_{\text {max }} * * *$ the temperature \\
corresponding to the maximum decomposition rate; ****VCNC \\
volumetric concentration (\%).
\end{tabular}

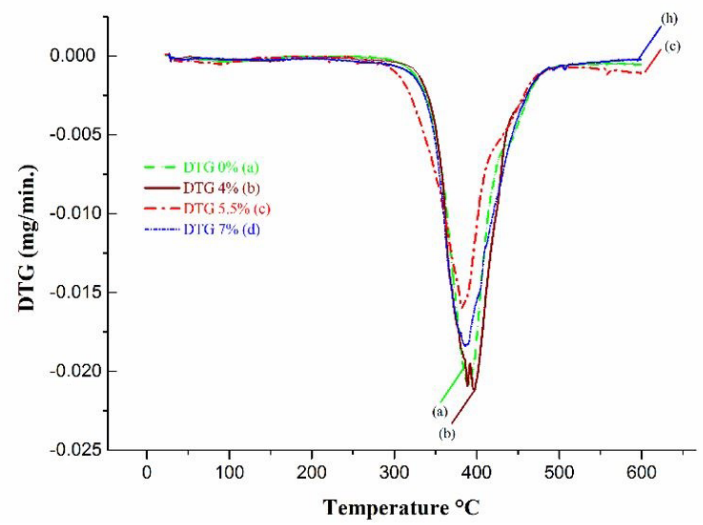

(b)

Figure 7. (a) TG curves and (b) Derivative TG analysis of pure epoxy resin and nanocomposites. 
Comparing the TG analysis curves of the pure epoxy system with the nanocomposites, it can be observed that the thermograms are similar. No specific degradation step of the CNCs is observed in the nanocomposite thermograms, regardless of the volumetric concentration.

It was observed for the nanocomposites that as the CNC content increased, all initial degradation temperatures decreased in relation to the pure epoxy. The $\mathrm{T}_{5 \%}$ for the pure epoxy was $338^{\circ} \mathrm{C}$, and this was reduced when $\mathrm{CNCs}$ were added for the range of 336 to $319^{\circ} \mathrm{C}$. This behavior has already been described in the literature, in which $\mathrm{T}_{\text {onset }}$ is around $320^{\circ} \mathrm{C}$ and it decreased when CNCs were added to the epoxy matrix, and is due to the lower $\mathrm{T}_{\text {onset }}$ temperature of the $\mathrm{CNCs}$, which is around $230^{\circ} \mathrm{C}^{[17,35]}$. Moreover, for $\mathrm{T}_{\text {max }}$, there was no relevant difference between the pure epoxy and the nanocomposites. Some of the divergent results due to the addition of CNCs can be explained by a complex energy dissipation mechanism of the interfaces between the nanocrystals and the matrix ${ }^{[19]}$. The $5.5 \%$ nanocomposite, which corresponds to the percolation threshold volume fraction, presented the lowest thermal stability of all samples. The slight decrease in $\mathrm{T}_{\max }$ for the 5.5 and $7.0 \%$ nanocomposites may have been due to increased thermal conductivity of the samples with the addition of the $\mathrm{CNCs}^{[36,37]}$.

\subsection{Mechanical testing}

There are many factors that directly affect the mechanical properties of nanocomposites, such as the inherent properties of the matrix and fillers, preparation conditions, interfacial adhesion (matrix-filler interaction), nanoparticle dispersion quality, and their concentration, which must be above the percolation threshold. Table 3 shows the results of the following mechanical properties: tensile modulus $\left(\mathrm{E}_{\mathrm{T}}\right)$, flexural modulus $\left(\mathrm{E}_{\mathrm{F}}\right)$, elongation in tensile $\left(\varepsilon_{\mathrm{T}}\right)$, elongation in flexural $\left(\varepsilon_{\mathrm{F}}\right)$, tensile strengths $\left(\boldsymbol{\sigma}_{\mathrm{T}}\right)$, flexural strengths $\left(\boldsymbol{\sigma}_{\mathrm{F}}\right)$ and impact strength (IS). The values of the modulus, the tensile strength and deformation for the tensile and flexural tests of the neat DGEBA/DEH24 are in accordance with other work in the literature ${ }^{[38]}$, but differ from those shown for the standard material ${ }^{[39]}$, which has a higher flexural modulus of $3.0 \mathrm{GPa}$ and lower tensile strength of $79 \mathrm{GPa}$. Table 3 also shows that the nanocomposites' tensile modulus and flexural modulus values were higher than that of the neat epoxy. This behavior indicates that the high surface area of the CNCs and the presence of O-H groups in their surface caused, at a certain level, good interaction of the $\mathrm{CNCs}$ with the epoxy resin molecules ${ }^{[17]}$, and includes possible chemical bonding between the CNCs and the epoxy matrix ${ }^{[40]}$. The values of elongation and tensile and flexural strengths have a tendency to reduction with the increase in the CNC concentration. Two main factors can explain this behavior: 1) the surface characteristics of the CNCs are an important issue in order to improve the mechanical properties, and in some cases their modification can be suggested ${ }^{[41]}$ and 2) the dispersion must ensure the availability of the surface for an adequate transfer of mechanical stress from the matrix to the filler. CNCs have a rigid nature and a tendency to form agglomerates that act as micro-particles distributed in the epoxy matrix, which caused stress concentration points in the epoxy matrix and made it rigid and hard ${ }^{[14,42]}$. Then, as the fraction of CNCs increased, the distribution of these agglomerates in the matrix also increased, and this caused the tensile and flexural moduli to increase, although in a lower proportion than expected. Furthermore, the agglomerates act as defects causing a premature fracture that reduces the elongation and strength. The TEM images shown in Figures 8a-c confirm the presence of the agglomerates in the nanocomposites.

The impact energy values for the nanocomposites were lower than those of the neat epoxy and the values decreased with the increase in the concentration of CNCs up to the concentration of $5.5 \%$ and, for the $7 \%$ concentration, there is a certain recovery in this property. This is in accordance with the results for the tensile and flexural values.

\subsection{Mechanical model for elastic modulus prediction}

Mechanical models help to validate experimental data. Most of them assume full or partial bonding between the reinforcement filler and the matrix. Among the best known for predicting the modulus of elasticity are the Mori-Tanaka models (based on the theory of inclusion and Eshelby's inclusion) and the Halpin-Tsai method (an interpretation of the Hill Potential theory). The latter is the most widely used to predict the modulus of elasticity of composites and

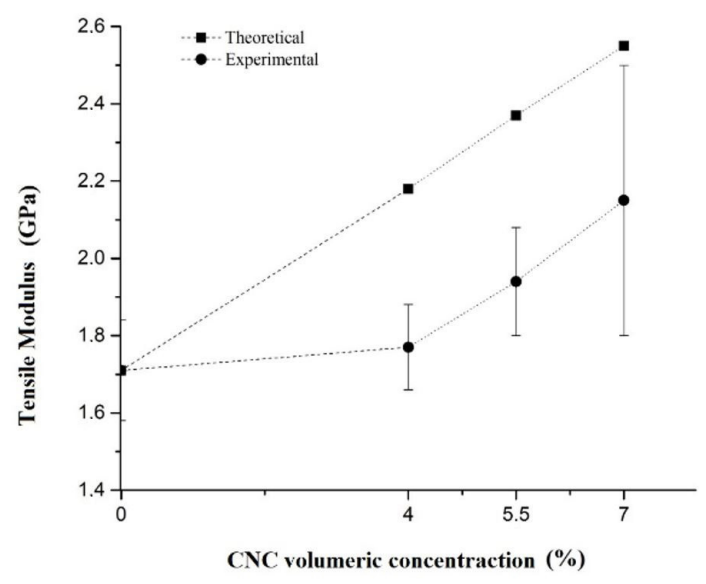

Figure 8. Theoretical and experimental tensile modulus of nanocomposites with different volume fractions.

Table 3. Mechanical properties of neat epoxy and nanocomposites.

\begin{tabular}{cccccccc}
\hline V CNC $(\%)$ & $\mathbf{E}_{\mathbf{T}}(\mathbf{G P a})$ & $\boldsymbol{\sigma}_{\mathbf{T}}(\mathbf{M P a})$ & $\boldsymbol{\varepsilon}_{\mathbf{T}}(\mathbf{\%})$ & $\mathbf{E}_{\mathbf{F}}(\mathbf{G P a})$ & $\boldsymbol{\sigma F}(\mathbf{M P a})$ & $\boldsymbol{\varepsilon}_{\mathbf{F}}(\mathbf{\%})$ & $\mathbf{I S}(\mathbf{J} / \mathbf{m})$ \\
\hline 0 & $1.70 \pm 0.13$ & $96 \pm 23$ & $2.7 \pm 0.9$ & $1.60 \pm 0.15$ & $73.2 \pm 1.8$ & $3.2 \pm 0.8$ & $4.8 \pm 0.3$ \\
4 & $1.77 \pm 0.11$ & $62 \pm 12$ & $2.0 \pm 0.1$ & $2.30 \pm 0.01$ & $61.6 \pm 3.1$ & $3.5 \pm 0.1$ & $3.9 \pm 0.1$ \\
5.5 & $1.94 \pm 0.14$ & $57 \pm 12$ & $1.5 \pm 0.6$ & $1.90 \pm 0.17$ & $50.6 \pm 10.8$ & $3.1 \pm 0.8$ & $3.7 \pm 0.6$ \\
7 & $2.15 \pm 0.35$ & $51 \pm 15$ & $1.3 \pm 0.6$ & $2.10 \pm 0.13$ & $67.6 \pm 8.5$ & $3.3 \pm 0.2$ & $4.3 \pm 0.3$ \\
\hline
\end{tabular}

${ }^{*} \mathrm{CNC}$ volumetric concentration (\%). 
is a relatively simple universal model that can be applied to various compounds ${ }^{[43]}$. In addition, it obtains and considers the form and aspect ratio of the reinforcement. The modified Halpin-Tsai model is presented in Equation 2. Coleman et al. ${ }^{[44]}$ states that this model provides better prediction of elastic modulus for low volumetric fractions.

$$
\mathrm{E}_{\mathrm{c}}=\frac{3}{8} \frac{1+2\left(\frac{\text { lf }}{\mathrm{df}}\right) \mathrm{n}_{\mathrm{L}} \mathrm{V}_{\mathrm{f}}}{1-\mathrm{n}_{\mathrm{L}} \mathrm{V}_{\mathrm{f}}} \mathrm{E}_{\mathrm{m}}+\frac{5}{8} \frac{1+2 \mathrm{n}_{\mathrm{T}} \mathrm{V}_{\mathrm{f}}}{1-\mathrm{n}_{\mathrm{T}} \mathrm{V}_{\mathrm{f}}} \mathrm{E}_{\mathrm{m}}
$$

In which: $\mathrm{E}_{\mathrm{c}}$ : elastic modulus of composites. $\mathrm{E}_{\mathrm{m}}$ : elastic modulus of epoxy matrix. $\mathrm{E}_{\mathrm{f}}$ : elastic modulus of fiber. $\mathrm{l}_{\mathrm{f}}=$ average fiber length. $\mathrm{d}_{\mathrm{f}}=$ average fiber diameter, $\mathrm{n}_{\mathrm{L}}=$ longitudinal efficiency factor and $\mathrm{n}_{\mathrm{T}}=$ transverse efficiency factor according to Equations 3 and 4, respectively.

$$
\begin{aligned}
& \mathrm{n}_{\mathrm{L}}=\frac{\left(\frac{\mathrm{E}_{\mathrm{f}}}{\mathrm{E}_{\mathrm{m}}}\right)-1}{\left(\frac{\mathrm{E}_{\mathrm{f}}}{\mathrm{E}_{\mathrm{m}}}\right)+2\left(\frac{1_{f}}{\mathrm{~d}_{\mathrm{f}}}\right)} \\
& \mathrm{n}_{\mathrm{T}}=\frac{\left(\frac{\mathrm{E}_{\mathrm{f}}}{\mathrm{E}_{\mathrm{m}}}\right)-1}{\left(\frac{\mathrm{E}_{\mathrm{f}}}{\mathrm{E}_{\mathrm{m}}}\right)+2}
\end{aligned}
$$

This model is useful for predicting the behavior of unidirectionally aligned composite materials and is used to evaluate the reinforcing effect of randomly oriented nanoparticles. It assumes that the dispersion of nanoparticles is uniform. Considering the dimensions obtained for the studied CNCs, they showed the necessary conditions for acting as reinforcement. According to the Halpin-Tsai model, the higher the aspect ratio, the larger the composite modulus. Figure 8 shows the theoretical and experimental results. Although the behavior of the experimental data is similar to the theoretical one, values are lower than those expected for nanocomposites, which shows that the studied system failed in some aspects. To elucidate this behavior, microanalyses are further discussed.

In addition to the Halpin-Tsai prediction model being used to calculate the modulus of elasticity, it was also used to estimate the form factor $(\xi)$. Since the elastic moduli of the components are known (Table 4), it was possible to theoretically evaluate the quality of the dispersion of the $\mathrm{CNCs}$ in the epoxy matrix. The form factor $(\xi)$ was derived from the Halpin-Tsai model in order to be applied to the nanocomposites. This model predicts Ec/Em (where Ec is the composite modulus and Em is the matrix modulus) and the value of $\xi$ for the best fit with the experimental results. The higher the value of $\xi$, the greater the indication of improvement in dispersion quality caused by the tendency of the nanoparticles to agglomerate ${ }^{[46]}$.

Figure 9 and Table 4 show that the dispersion quality is higher for smaller volume fractions. As can be seen, the proximity of the line of the experimental relative modulus is greater for $\xi=10$. As the volumetric fractions of the CNCs increase, the quality of the dispersion decreases. The dispersion of nanoparticles is a crucial factor for improving the resistance properties. This may explain the mechanical properties. The sample with $4 \%$ and $5.5 \%$ of CNCs showed better dispersion according to the model, which may justify this sample having greater rupture stress than the samples with larger volumetric fractions of CNCs. Therefore, where there is better dispersion, there is also an increase in rupture stress ${ }^{[45]}$.

Figures 10a-c shows the TEM images of the epoxy/ $\mathrm{CNC}$ nanocomposites. The presence of the $\mathrm{CNCs}$ can be observed at various scales, as well as their dispersion in the epoxy matrix. The images show aggregations of $\mathrm{CNCs}$ in all the nanocomposites, as well as their non-uniform dispersion in the matrix. Ultrasound was applied in order to favor the dispersion of the CNCs in the matrix; however, the dispersion was not uniform and had the formation of aggregations, which may explain the poor performance regarding the mechanical properties in relation to the neat matrix. Uniform and good dispersion of the CNCs in the matrix tends to improve mechanical properties and tends to make the percolation theory applicable ${ }^{[47]}$. Figure $10 \mathrm{~d}$ shows an image with a greater magnitude of CNC aggregations in the epoxy matrix, and it is possible to observe its morphology.

The lack of a better reinforcing effect could be explained by the hydrophilic nature of $\mathrm{CNCs}^{[40]}$, which causes them to

\begin{tabular}{|c|c|c|}
\hline $\begin{array}{c}\text { Vf } \\
(4 \% \text { CNCs) }\end{array}$ & $\operatorname{Vf}(5.5 \% \mathrm{CNCs})$ & $\begin{array}{c}\text { Vf } \\
(7 \% \text { CNCs) }\end{array}$ \\
\hline \multicolumn{3}{|c|}{ Ec (GPa) } \\
\hline 1.77 & 1.94 & \multirow[t]{2}{*}{2.14} \\
\hline & $\operatorname{Ec} / \operatorname{Em}(\xi=5)$ & \\
\hline 1.11 & 1.16 & \multirow[t]{2}{*}{1.20} \\
\hline & $\operatorname{Ec} / \operatorname{Em}(\xi=10)$ & \\
\hline 1.07 & 1.10 & \multirow[t]{2}{*}{1.14} \\
\hline & Experimental & \\
\hline 1.03 & 1.13 & 1.25 \\
\hline $\mathbf{E}_{\mathrm{CNC}}(\mathrm{GPa})$ & \multicolumn{2}{|c|}{ Em (GPa) } \\
\hline $50^{[55]}$ & \multicolumn{2}{|c|}{1.70} \\
\hline
\end{tabular}

Table 4. Values of the tensile modulus of the composites, matrix and CNCs.

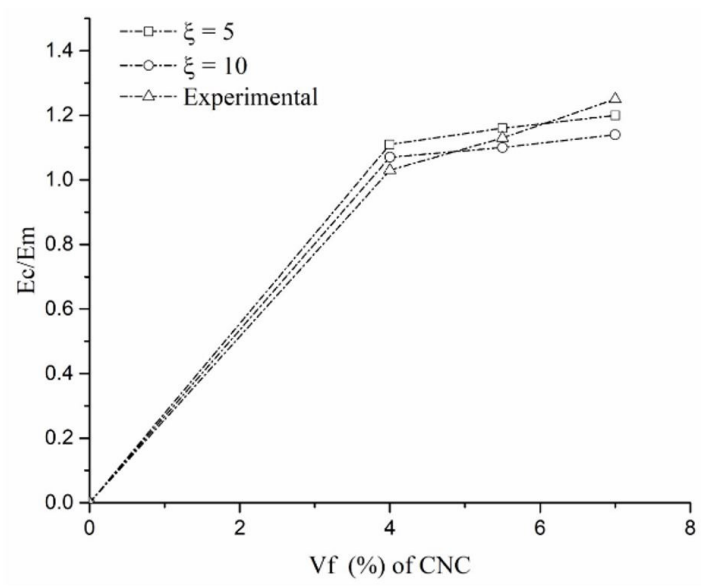

Figure 9. Comparison of experimental data with those predicted for the effect of $\mathrm{Vf}(\mathrm{CNCs})$ (fraction of volume in percentage) on the relative modulus of epoxy nanocomposites $+\mathrm{CNCs}$. 

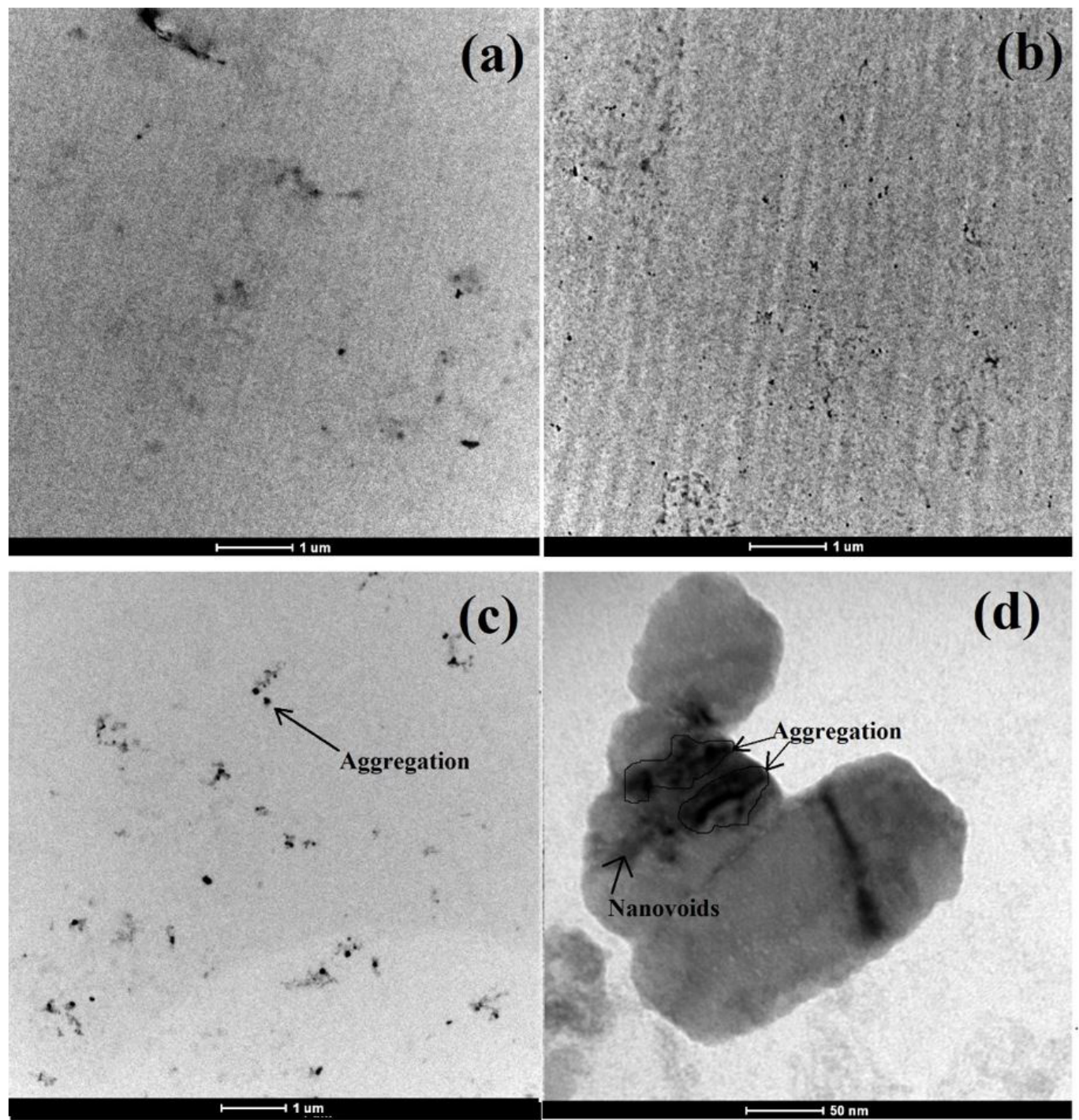

Figure 10. TEM images of nanocomposites (a) 4\% CNCs, (b) $5.5 \% \mathrm{CNCs}$, (c) $7 \% \mathrm{CNCs}$, (Magnitude of 40,000 X) and (d) details of aggregation of CNCs ( $4 \%$ CNCs) (Magnitude of 200,000 X).

have a poor interaction with the epoxy matrix ${ }^{[33,42]}$. Besides the lack of dispersion, the presence of water in the structure of the epoxy matrix can greatly affect the mechanical properties of nanocomposites ${ }^{[48]}$. The slight reduction in the $\mathrm{Tg}$ values of the nanocomposites $\left(5^{\circ} \mathrm{C}\right.$ for the 5.5 and $7 \% \mathrm{CNCs}$ ) shows that residues of water molecules on the surfaces of the $\mathrm{CNC}$ aggregations may have caused cellulose degradation. The molecules resulting from the degradation increased the free volume of the network structure of the epoxy matrix and, consequently, reduced the mechanical properties of the nanocomposites ${ }^{[28]}$. The presence of CNCs in the epoxy matrix may also have hindered the crosslinking of the epoxy resin ${ }^{[49]}$, though the conversion was quite similar for all samples, which leads us to disregard this effect.

The samples with $7 \%$ CNCs showed that, even with the $\mathrm{CNC}$ aggregation, it may also have had better dispersion of $\mathrm{CNCs}$ and a better interfacial interaction with the matrix, and this led to greater toughness (IS) when compared to other nanocomposites. The reduction of impact energy for nanocomposites is explained by the same reason, i.e., the CNC aggregations ${ }^{[42,50]}$.

The SEM images in Figures 11a-h show the effect of the CNCs on the fractured surfaces of the tensile tested samples. Neat epoxy resin (Figure 11a) has a smooth, homogenous and glassy region and semi-elliptical marks and steps ${ }^{[51]}$. The surface pattern indicates a low resistance to crack propagation that led to brittle failure ${ }^{[52]}$. The behavior in Figure $11 \mathrm{~b}$, marked by a black arrow, revealed its typical brittle nature with poor resistance to cracking or rupturing and its tendency towards propagation ${ }^{[53,54]}$. Figures $11 \mathrm{c}-\mathrm{h}$ show the SEM micrographs of the nanocomposites with 4.0, 5.5 and 7.0\% CNCs. The incorporation of CNCs caused the roughness in the nanocomposite fractures observed in Figures $11 \mathrm{c}, \mathrm{e}$, and g. In the images, the black arrows show that the CNCs increase the roughness, similar to what was observed by Kumar et al. ${ }^{[40]}$. Based on the images and on 

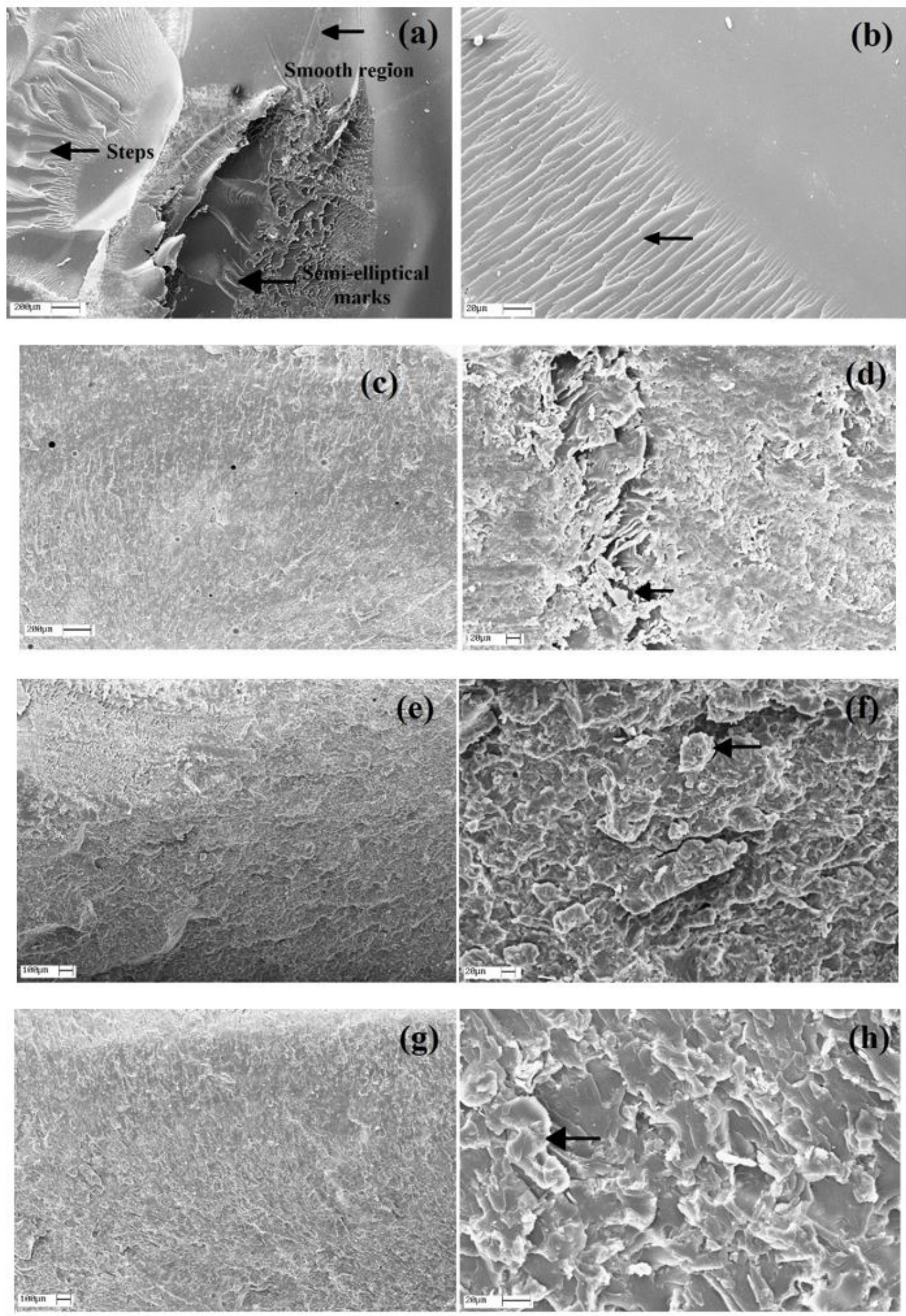

Figure 11. SEM micrographs of resin and nanocomposite (a) and (b) neat epoxy; (c) and (d) $4.0 \% \mathrm{CNCs}$; (e) and (f) $5.5 \% \mathrm{CNCs}$; and (g) and (h) $7.0 \%$ CNCs. 
the mechanical properties, we can state that, during the deformation, the CNCs reinforced the system and increased the elastic modulus, but accelerated the fracture by acting as point defects.

\section{Conclusions}

The CNCs obtained from microcrystalline cellulose using the acid hydrolysis method presented a high degree of crystallinity, with around $82.7 \%$ of the majority being cellulose I with dimensions of length and diameter of $(142 \pm 36) \mathrm{nm}$ and $(11 \pm 2.5) \mathrm{nm}$, respectively, which resulted in an aspect ratio of 12.5 . This fibrous morphology led to the calculation of the volume fraction percolation threshold of $5.5 \%$. Analysis of the epoxy/CNC nanocomposites showed that the addition of CNCs caused minor changes in the cure conversion and in the thermal properties. The mechanical tensile tests showed an increase in elastic modulus, but the expected abrupt increase over the percolation threshold was not observed. The Halpin-Tsai modulus of elasticity prediction model was applied and showed coherence in the curve tendency, though the experimental results were lower than the prediction, which was attributed to the lack of dispersion of the CNCs and the weak interaction between the phases. Impact resistance and the flexural modulus showed decreases when compared to pure resin. The lack of a better reinforcing effect may be explained by the hydrophilic nature of CNCs, which cause them to have a poor interaction with the epoxy matrix and/or by the lyophilized CNC aggregation, which shows that the applied dispersion process was not capable of uniformly dispersing the $\mathrm{CNCs}$ in the matrix.

\section{References}

1. Nguyen, D. A., Lee, Y. R., Raghu, A. V., Jeong, H. M., Shin, C. M., \& Kim, B. K. (2009). Morphological and physical properties of a thermoplastic polyurethane reinforced with functionalized graphene sheet. Polymer International, 58(4), 412-417. http://dx.doi.org/10.1002/pi.2549.

2. Potts, J. R., Dreyer, D. R., Bielawski, C. W., \& Ruoff, R. S. (2011). Graphene-based polymer nanocomposites. Polymer, 52(1), 5-25. http://dx.doi.org/10.1016/j.polymer.2010.11.042.

3. Kumar, S. K., \& Krishnamoorti, R. (2010). Nanocomposites: structure, phase behavior, and properties. Annual Review of Chemical and Biomolecular Engineering, 1(1), 37-58. http:// dx.doi.org/10.1146/annurev-chembioeng-073009-100856. PMid:22432572.

4. Xie, S., Zhang, X., Walcott, M. P., \& Lin, H. (2018). Applications of cellulose nanocrystals: a review. Engineering and Science, 2, 4-16. http://dx.doi.org/10.30919/es.1803302.

5. Miao, C., \& Hamad, W. Y. (2016). In-situ polymerized cellulose nanocrystals (CNC) poly(l-lactide) (PLLA) nanomaterials and applications in nanocomposite processing. Carbohydrate Polymers, 153, 549-558. http://dx.doi.org/10.1016/j.carbpol.2016.08.012. PMid:27561528.

6. Bonini, C., Heux, L., \& Cavaillé, J.-Y. (2000). Polypropylene reinforced with cellulose whiskers. Matériaux \& Techniques, 88(7-8), 55-58. http://dx.doi.org/10.1051/mattech/200088070055.

7. Yu, T., Soomro, S., Huang, F., Wei, W., Wang, B., Zhou, Z., \& Hui, D. (2020). Naturally or artificially constructed nanocellulose architectures for epoxy composites: a review.
Nanotechnology Reviews, 9(1), 1643-1659. http://dx.doi. org/10.1515/ntrev-2020-0116.

8. Habibi, Y., Lucia, L. A., \& Rojas, O. J. (2010). Cellulose nanocrystals: chemistry, self-assembly, and applications. Chemical Reviews, 110(6), 3479-3500. http://dx.doi.org/10.1021/ cr900339w. PMid:20201500.

9. Li, S., Jasim, A., Zhao, W., Fu, L., Ullah, M. W., Shi, Z., \& Yang, G. (2018). Fabrication of pH-electroactive bacterial cellulose/ polyaniline hydrogel for the development of a controlled drug release system. ES Materials \& Manufacturing, 1, 41-49. http:// dx.doi.org/10.30919/esmm5f120.

10. Cai, J., Xu, W., Liu, Y., Zhu, Z., Liu, G., Ding, W., Wang, G., Wang, H., \& Luo, Y. (2019). Robust construction of flexible bacterial cellulose@ $\mathrm{Ni}(\mathrm{OH})_{2}$ paper: toward high capacitance and sensitive $\mathrm{H}_{2} \mathrm{O}_{2}$ detection. Engineered Science, 5, 21-29. http://dx.doi.org/10.30919/es8d669.

11. He, Y., Chen, Q., Yang, S., Lu, C., Feng, M., Jiang, Y., Cao, G., Zhang, J., \& Liu, C. (2018). Micro-crack behavior of carbon fiber reinforced $\mathrm{Fe} 3 \mathrm{O} 4 /$ graphene oxide modified epoxy composites for cryogenic application. Composites. Part A, Applied Science and Manufacturing, 108, 12-22. http://dx.doi. org/10.1016/j.compositesa.2018.02.014.

12. Song, B., Wang, T., Sun, H., Liu, H., Mai, X., Wang, X., Wang, L., Wang, N., Huang, Y., \& Guo, Z. (2018). Graphitic carbon nitride (g-C3N4) interfacially strengthened carbon fiber epoxy composites. Composites Science and Technology, 167, 515-521. http://dx.doi.org/10.1016/j.compscitech.2018.08.031.

13. Ma, L., Zhu, Y., Feng, P., Song, G., Huang, Y., Liu, H., Zhang, J., Fan, J., Hou, H., \& Guo, Z. (2019). Reinforcing carbon fiber epoxy composites with triazine derivatives functionalized graphene oxide modified sizing agent. Composites. Part B, Engineering, 176, 107078. http://dx.doi.org/10.1016/j. compositesb.2019.107078.

14. Wu, G.-M., Liu, D., Liu, G.-F., Chen, J., Huo, S.-P., \& Kong, Z.-W. (2015). Thermoset nanocomposites from waterborne bio-based epoxy resin and cellulose nanowhiskers. Carbohydrate Polymers, 127, 229-235. http://dx.doi.org/10.1016/j.carbpol.2015.03.078. PMid:25965479.

15. Roszowska-Jarosz, M., Masiewicz, J., Kostrzewa, M., Kucharczyk, W., Zurowski, W., Kucinska-Lipka, J., Przybyłek, P. (2021). Mechanical Properties of Bio-Composites Based on Epoxy Resin and Nanocellulose Fibres. Materials, 14, 1-16. https:// doi.org/10.3390/ma14133576.

16. Nissilä, T., Hietala, M., \& Oksman, K. (2019). A method for preparing epoxy-cellulose nanofiber composites with anoriented structure. Composites. Part A, Applied Science and Manufacturing, 125, 105515. http://dx.doi.org/10.1016/j. compositesa.2019.105515.

17. Qin, X., Ge, W., Mei, H., Li, L., \& Zheng, S. (2021). Toughness improvement of epoxy thermosets with cellulose nanocrystals. Polymer International, 70(1), 1640-1648. http://dx.doi. org/10.1002/pi.6260.

18. Yue, L., Ke, K., Amirkhosravi, M., Gray, T. G., \& ManasZloczower, I. (2021). Catalyst-free mechanochemical recycling of biobased epoxy with cellulose nanocrystals. ACS Applied Bio Materials., 4(5), 4176-4183. http://dx.doi.org/10.1021/ acsabm.0c01670.

19. Hassan, M. L., Bras, J., Hassan, E. A., Fadel, S. M., \& Dufresne, A. (2012). Polycaprolactone/modified bagasse whisker nanocomposites with improved moisture-barrier and biodegradability properties. Journal of Applied Polymer Science, 125(S2), E10-E19. http://dx.doi.org/10.1002/app.36373.

20. Samir, A. S. A., Alloin, F., \& Dufresne, A. (2005). Review of recent research into cellulosic whiskers, their properties and their application in nanocomposite field. Biomacromolecules, 6(2), 612-626. http://dx.doi.org/10.1021/bm0493685. PMid:15762621. 
21. Omrani, A., Simon, L. C., \& Rostami, A. A. (2008). Influences of cellulose nanofiber on the epoxy network formation. Materials Science and Engineering A, 490(1-2), 131-137. http://dx.doi. org/10.1016/j.msea.2008.01.012.

22. Martin, A. R., Martins, M. A., Mattoso, L. H. C., \& Silva, O. R. R. F. (2009). Chemical and structural characterization of sisal fibers from Agave sisalana variety. Polímeros: Ciência e Tecnologia, 19(1), 40-46. http://dx.doi.org/10.1590/S010414282009000100011 .

23. Ciolacu, D., Ciolacu, F., \& Popa, V. I. (2011). Amorphous cellulose - structure and characterization. Cellulose Chemistry and Technology, 45(1-2), 13-21. Retrieved in 2021, October 10, from https://cellulosechemtechnol.ro/pdf/CCT1-2(2011)/p.13-21. pdf

24. Pandey, J. K., Lee, C. S., \& Ahn, S.-H. (2010). Preparation and properties of bio-nanoreinforced composites from biodegradable polymer matrix and cellulose whiskers. Journal of Applied Polymer Science, 115(4), 2493-2501. http://dx.doi.org/10.1002/ app.31205.

25. Rosa, M. F., Medeiros, E. S., Malmonge, J. A., Gregorski, K. S., Wood, D. F., Mattoso, L. H. C., Glenn, G., Orts, W. J., \& Imam, S. H. (2010). Cellulose nanowhiskers from coconut husk fibers: effect of preparation conditions on their thermal and morphological behavior. Carbohydrate Polymers, 81(1), 83-92. http://dx.doi.org/10.1016/j.carbpol.2010.01.059.

26. Adel, A. M., Abd El-Wahab, Z. H., Ibrahim, A. A., \& AlShemy, M. T. (2016). Characterization of microcrystalline cellulose prepared from lignocellulosic materials. Part II: physicochemical properties. Carbohydrate Polymers, 83(2), 676-687. http://dx.doi.org/10.1016/j.carbpol.2010.08.039.

27. Azeredo, H. M. C., Mattoso, L. H. C., Wood, D., Williams, T. G., Avena-Bustillos, R. J., \& McHugh, T. H. (2009). Nanocomposite edible films from mango puree reinforced with cellulose nanofibers. Journal of Food Science, 74(5), N31-N35. http://dx.doi.org/10.1111/j.1750-3841.2009.01186.x. PMid:19646052.

28. Trinh, B. M., \& Mekonnen, T. (2018). Hydrophobic esterification of cellulose nanocrystals for epoxy reinforcement. Polymer, 155, 64-74. http://dx.doi.org/10.1016/j.polymer.2018.08.076.

29. Hardis, R., Jessop, J. L. P., Peters, F. E., \& Kessler, M. R. (2013). Cure kinetics characterization and monitoring of an epoxy resin using DSC, Raman spectroscopy, and DEA. Composites. Part A, Applied Science and Manufacturing, 49, 100-108. http://dx.doi.org/10.1016/j.compositesa.2013.01.021.

30. González-Garcia, F., Miguez, E., \& Soares, B. G. (2005). Characterization of diglycidyl ether of bisphenol A / aliphatic polyamines systems. Polímeros: Ciência e Tecnologia, 15(4), 261-267. http://dx.doi.org/10.1590/S0104-14282005000400010.

31. Silverstein, R. M., \& Bassler, G. C. (1962). Spectrometric identification of organic compounds. Journal of Chemical Education, 39(11), 546. http://dx.doi.org/10.1021/ed039p546.

32. Mandal, A., \& Chakrabarty, D. (2011). Isolation of nanocellulose from waste sugarcane bagasse (SCB) and its characterization. Carbohydrate Polymers, 86(3), 1291-1299. http://dx.doi. org/10.1016/j.carbpol.2011.06.030.

33. Xu, S., Girouard, N., Schueneman, G., Shofner, M. L., \& Meredith, J. C. (2013). Mechanical and thermal properties of waterborne epoxy composites containing cellulose nanocrystals. Polymer, 54(24), 6589-6598. http://dx.doi.org/10.1016/j. polymer.2013.10.011.

34. Johnson, D. J., Compton, D. A. C., Cass, R. S., \& Canale, P. L. (1993). The characterization of amine-activated epoxies as a function of cure by using TGA/FT-IR. Thermochimica Acta, 203, 293-308. http://dx.doi.org/10.1016/0040-6031(93)80367-J.

35. Miyagawa, H., \& Drzal, L. T. (2004). Thermo-physical and impact properties of epoxy nanocomposites reinforced by single-wall carbon nanotubes. Polymer, 45(15), 5163-5170. http://dx.doi.org/10.1016/j.polymer.2004.05.036.

36. Tang, L., \& Weder, C. (2010). Cellulose whisker/epoxy resin nanocomposites. ACS Applied Materials \& Interfaces, 2(4), 10731080. http://dx.doi.org/10.1021/am900830h. PMid:20423128.

37. Shimazaki, Y., Miyazaki, Y., Takezawa, Y., Nogi, M., Abe, K., Ifuku, S., \& Yano, H. (2007). Excellent thermal conductivity of transparent cellulose nanofiber/epoxy resin nanocomposites. Biomacromolecules, 8(9), 2976-2978. http://dx.doi.org/10.1021/ bm7004998. PMid:17696397.

38. González-Garcia, F., Soares, B. G., Pita, V. J. R. R., Sánchez, R., \& Rieumont, J. (2007). Mechanical properties of epoxy networks based on DGEBA and aliphatic amines. Journal of Applied Polymer Science, 106(4), 2047-2055. http://dx.doi. org/10.1002/app.24895.

39. CSTJ Materiaux Composites. (2021, October 10). Product information: D.E.R. ${ }^{\mathrm{TM}} 331^{\mathrm{TM}}$. Retrieved in 2021, October 10 , from https://cstjmateriauxcomposites.files.wordpress. com/2017/11/der331.pdf

40. Kumar, S., Falzon, B. G., Kun, J., Wilson, E., Graninger, G., $\&$ Hawkins, S. C. (2020). High performance multiscale glass fibre epoxy composites integrated with cellulose nanocrystals for advanced structural applications. Composites. Part A, Applied Science and Manufacturing, 131, 105801. http:// dx.doi.org/10.1016/j.compositesa.2020.105801.

41. Peng, S. X., Shrestha, S., Yoo, Y., \& Youngblood, J. P. (2017). Enhanced dispersion and properties of a two-component epoxy nanocomposite using surface modified cellulose nanocrystals. Polymer, 112, 359-368. http://dx.doi.org/10.1016/j. polymer.2017.02.016.

42. Saba, N., Mohammad, F., Pervaiz, M., Jawaid, M., Alothman, O. Y., \& Sain, M. (2017). Mechanical, morphological and structural properties of cellulose nanofibers reinforced epoxy composites. International Journal of Biological Macromolecules, 97, 190-200. http://dx.doi.org/10.1016/j.ijbiomac.2017.01.029. PMid:28082223.

43. Krishnamoorti, R., Ren, J., \& Silva, A. S. (2001). Shear response of layered silicate nanocomposites. The Journal of Chemical Physics, 114(11), 4968-4973. http://dx.doi. org/10.1063/1.1345908.

44. Coleman, J. N., Khan, U., Blau, W. J., \& Gun'ko, Y. K. (2006). Small but strong: a review of the mechanical properties of carbon nanotube-polymer composites. Carbon, 44(9), 16241652. http://dx.doi.org/10.1016/j.carbon.2006.02.038.

45. El Miri, N., Abdelouahdi, K., Barakat, A., Zahouily, M., Fihri, A., Solhy, A., \& El Achaby, M. (2015). Bio-nanocomposite films reinforced with cellulose nanocrystals: rheology of film-forming solutions, transparency, water vapor barrier and tensile properties of films. Carbohydrate Polymers, 129, 156-167. http://dx.doi.org/10.1016/j.carbpol.2015.04.051. PMid:26050901.

46. Laghaei, R., Fashandi, H., Hejazi, S. M., Shaghaghi, S., \& Shamaei-Kashani, A. (2021). Enhancing mechanical properties of biaxial E-glass fabric/epoxy composite using cellulose nanocrystals: impact of mixing medium. Journal of Composite Materials, 55(24), 3325-3343. http://dx.doi. org/10.1177/00219983211013388.

47. Qi, B., Zhang, Q. X., Bannister, M., \& Mai, Y.-W. (2006). Investigation of the mechanical properties of DGEBA-based epoxy resin with nanoclay additives. Composite Structures, 75(1-4), 514-519. http://dx.doi.org/10.1016/j.compstruct.2006.04.032.

48. Blanco, I., Cicala, G., Costa, M., \& Recca, A. (2006). Development of an epoxy system characterized by low water absorption and high thermomechanical performances. Journal of Applied Polymer Science, 100(6), 4880-4887. http://dx.doi. org/10.1002/app.23276. 
49. Asaro, L., Seoane, I. T., Fasce, L. A., Cyras, V. P., \& Manfredi, L. B. (2019). Development of low environmental impact protective coatings based on a furan resin and cellulose nanocrystals. Progress in Organic Coatings, 133, 229-236. http://dx.doi.org/10.1016/j.porgcoat.2019.04.035.

50. Zhang, Y., Song, P., Liu, H., Li, Q., \& Fu, S. (2016). Morphology, healing and mechanical performance of nanofibrillated cellulose reinforced poly ( $\varepsilon$-caprolactone)/epoxy. Composites Science and Technology, 125, 62-70. http://dx.doi.org/10.1016/j. compscitech.2016.01.008.

51. Alamri, H., \& Low, I. M. (2012). Mechanical properties and water absorption behaviour of recycled cellulose fibre reinforced epoxy composites. Polymer Testing, 31(5), 620-628. http:// dx.doi.org/10.1016/j.polymertesting.2012.04.002.

52. Gonçalves, J. A. V., Campos, D. A. T., Oliveira, G. J., Rosa, M. L. S., \& Macêdo, M. A. (2014). Mechanical properties of epoxy resin based on granite stone powder from the Sergipe
Fold-and-thrust belt composites. Materials Research, 17(4), 878-887. http://dx.doi.org/10.1590/S1516-14392014005000100.

53. Dadfar, M. F., \& Ghadami, F. (2013). Effect of rubber modification on fracture toughness properties of glass reinforced hot cured epoxy composites. Materials \& Design, 47, 16-20. http://dx.doi. org/10.1016/j.matdes.2012.12.035.

54. Quan, D., \& Ivankovic, A. (2015). Effect of core-shell rubber (CSR) nano-particles on mechanical properties and fracture toughness of an epoxy polymer. Polymer, 66, 16-28. http:// dx.doi.org/10.1016/j.polymer.2015.04.002.

55. Lahiji, R. R., Xu, X., Reifenberger, R., Raman, A., Rudie, A., \& Moon, R. J. (2010). Atomic force microscopy characterization of cellulose nanocrystals. Langmuir, 26(6), 4480-4488. http:// dx.doi.org/10.1021/la903111j. PMid:20055370.

Received: Aug. 12, 2021

Revised: Oct. 22, 2021

Accepted: Nov. 26, 2021 